\title{
Tailor-Made Macromolecules by Carbocationic Techniques
}

\author{
Joseph P. KENNEDY \\ Institute of Polymer Science, The University of Akron, \\ Akron, Ohio 44325, U.S.A.
}

(Received April 15, 1980)

\begin{abstract}
Recent insight into the mechanism of carbocationic polymerizations have led to significant advances toward the synthesis of many types of unique well-defined macromolecules. Elucidation of details of initiation yielded polyisobutylylstyrene macromer $\mathrm{CH}_{2}=\mathrm{CH}-\mathrm{C}_{6} \mathrm{H}_{4}-\mathrm{PIB}$, the free-radical solution copolymerization of which with various acrylates led to new grafts, e.g., poly(butyl acrylate- $g$-isobutylene). The inifer technique led to $\alpha, \omega$-di( $t$-chloro)polyisobutylene which was converted in $100 \%$ yield to $\alpha, \omega$-bis(2-methyl-2-propenyl)polyisobutylene which upon hydroboration and alkaline oxidation resulted in $100 \%$ yield in $\alpha, \omega$-bis(3-hydroxyl-2-methylpropyl)polyisobutylene, $\mathrm{HOCH}_{2}-\mathrm{PIB}-\mathrm{CH}_{2} \mathrm{OH}$. Extensive characterization research of the latter $\alpha, \omega$-primary diol indicated $\bar{F}_{n}$ (average terminal functionality) $=2.0$. This $\alpha, \omega$-primary diol in conjunction with 2,4-toluene diisocyanate gave new polyurethanes with polyisobutylene soft segments. On account of their saturated hydrocarbon soft-segments these polyurethanes promise to exhibit improved UV, chemical and hydrolytic stability. Analysis of kinetic factors that control the rates of termination, chain transfer to monomer, initiation and propagation, $R_{\mathrm{t}}, R_{\mathrm{t}, \mathrm{M}}, R_{\mathrm{i}}, R_{\mathrm{p}}$, led to the prediction and subsequent experimental demonstration of quasiliving carbocationic polymerizations. Under quasiliving conditions the system behaves as though $R_{\mathrm{t}}=0, R_{\mathrm{t}, \mathrm{M}}=0$, and $R_{\mathrm{i}}>R_{\mathrm{p}}$. Quasiliving polymerizations have been obtained with $\alpha$-methylstyrene and isobutylene monomers. The molecular weights of polymers obtained under quasiliving conditions obey $\overline{D P}_{n}=M_{\text {total }} /[\mathrm{I}]_{0}$, where $M_{\text {total }}$ is monomer input and $[\mathrm{I}]_{0}$ is initial initiator concentration. Increased understanding of termination processes led to polymers with desirable terminal functionalities, e.g., chlorine, cyclopentadiene, and phenyl. The controlled combination of mechanistic elements, i.e., controlled initiation, propagation (absence of chain transfer to monomer) and termination has resulted in the synthesis of the first graft-block copolymer, poly[chloroprene- $g$-(isobutylene- $b-\alpha-$ methylstyrene)] by carbocationic techniques.
\end{abstract}

KEY WORDS Macromer / Grafts / Inifer / $\alpha, \omega$-Primary Diol / Polyurethanes / Polyisobutylene / Quasiliving / Graft-Block Copolymer /

Research in our laboratories since about 10 years has focused on the detailed elucidation of the mechanism of cationic, particularly carbocationic, polymerizations as a means toward the synthesis of new architectures with desirable properties. This approach was fruitful and our increased understanding of initiation, propagation, chain transfer, particularly chain transfer to monomer, and termination reactions yielded a great variety of new types of polymers including grafts, blocks, telechelics and macromers. In this presentation we will briefly survey recent achievements realized by gaining insight into the details of the above elementary events, particularly in the areas of controlled initiation, i.e., preparation of new macromers by controlled initiation, and controlled propagation, i.e., propagation in the absence of chain transfer to monomer by the use of the inifer technique. Also, the new concept of quasiliving polymerizations as a means to molecular-weight and molecular-weightdistribution control will be outlined and illustrated with an example. Finally we will outline the synthesis of the first graft-block copolymer, poly[chloroprene- $g$-(isobutylene- $b$ - $\alpha$-methylstyrene)], by cationic technique.

\section{RESULTS AND DISCUSSION}

\section{Initiation}

Initiation in carbocationic polymerization usually 


\section{J. P. KENNEDY}

consists of a slow ion-generation step followed by relatively faster cationation of monomer:

$$
\begin{aligned}
& \mathrm{RX}+\mathrm{MX}_{n} \rightleftarrows \mathrm{R}^{\oplus} \mathrm{MX}_{n+1}^{\ominus} \\
& \mathrm{R}^{\oplus}+\mathrm{C}=\mathrm{C} \longrightarrow \mathrm{R}-\mathrm{C}-\mathrm{C}^{\oplus}
\end{aligned}
$$

where $\mathrm{RX}$, initiator; $\mathrm{MX}_{n}$, coinitiator; and $\mathrm{C}=\mathrm{C}$, monomer. A consequence of the understanding of these events was the development of a new grafting technique $^{1}$ still under intensive investigation by several groups in the U.S.A. and abroad. Table I summarizes the great variety of grafts prepared by

Table I. Graft copolymers prepared by carbocationic techniques

I. Elastomeric backbones

A) Elastomeric branches

Poly(butadiene- $g$-isobutylene) ${ }^{\mathrm{a}}$

Poly(chloroprene- $g$-isobutylene)

Poly[chloroprene- $g$-(isobutylene-co-isoprene)]

Poly[chloroprene- $g$-(isobutylene- $b-\alpha$-methylstyrene)]

Poly(chloroprene- $g$-isobutyl vinyl ether)

Poly[(styrene-co-butadiene)- $g$-isobutylene $]^{\mathrm{a}}$

Poly[(isobutylene-co-isoprene)- $g$-chloroprene $]^{\mathrm{a}}$

B) Glassy branches

Poly[(ethylene-co-propylene)- $g$-styrene ${ }^{\mathrm{a}}$

Poly[(ethylene-co-propylene)- $g$-indene $]^{\mathrm{a}}$

Poly[(isobutylene-co-isoprene)- $g$-styrene] ${ }^{\mathrm{a}, \mathrm{b}}$

Poly[(isobutylene-co-isoprene)- $g$ - $\alpha$-methylstyrene $]^{\mathrm{a}}$

Poly[(isobutylene-co-isoprene)-g- $p$-chlorostyrene $]^{\mathrm{a}}$

Poly[(isobutylene-co-isoprene)- $g$-indene $]^{\mathrm{a}}$

Poly[(isobutylene-co-isoprene)- $g$-(indene-co- $\alpha$-methylstyrene) $]^{\mathrm{a}}$

Poly[(isobutylene-co-isoprene)- $g$-acenaphthylene $]^{\mathrm{a}}$

Poly[(isobutylene-co-p-chloromethylstyrene)- $g$-indene]

Poly[(isobutylene-co- $p$-chloromethylstyrene)- $g$ - $\alpha$-methylstyrene]

Poly(chloroprene- $g$-styrene)

Poly(butadiene- $g$ - $\alpha$-methylstyrene) ${ }^{a}$

Chlorosulfonated polyethylene- $g$-polystyrene

Poly[( $p$-chloromethylstyrene-co-butadiene)- $g$-styrene]

C) Two branches (bigrafts)

1. A glassy and an elastomeric branch

Poly[(ethylene-co-propylene-co-1,4-hexadiene)- $g$-styrene- $g$-isobutylene $]^{\mathrm{a}, \mathrm{b}}$

Poly[(ethylene-co-propylene-co-1,4-hexadiene)- $g$ - $\alpha$-methylstyrene- $g$-isobutylene $]^{\mathrm{a}, \mathrm{b}}$

2. Two glassy branches Poly[(ethylene-co-propylene-co-1,4-hexadiene)- $g$-styrene- $g$ - $\alpha$-methylstyrene $]^{\mathrm{a}, \mathrm{b}}$

II. Glassy backbones

A) Elastomeric branches

Poly(vinyl chloride- $g$-isobutylene)

Poly[vinyl chloride- $g$-(isobutylene- $c o$-isoprene)]

Chloromethylated polystyrene- $g$-polyisobutylene

Chlorinated poly(vinyl chloride)- $g$-polybutadiene

Chlorinated polycyclopentadiene- $g$-polybutadiene

B) Glassy branches

Poly(vinyl chloride- $g$-styrene)

a Lightly cniorinated backbone used.

b Lightly brominated backbone used. 
this technique to date.

Recent advances in this field are the surface grafting of polypropylene fibers ${ }^{2}$ and silicas. $^{3}$ Isotactic polypropylene fibers were surfacechlorinated by the use of a continuous plasma process and the slightly chlorinated fibers were employed in the presence of $\mathrm{Et}_{2} \mathrm{AlCl}$ to initiate the polymerization of styrene. ${ }^{2}$ Silica surfaces were treated with $\mathrm{Cl}\left(\mathrm{CH}_{3}\right)_{2} \mathrm{Si}-\mathrm{CH}_{2} \mathrm{CH}_{2} \mathrm{C}_{6} \mathrm{H}_{4}-\mathrm{CH}_{2} \mathrm{Cl}$ :<smiles>C[Si](C)(CCc1ccc(Cl)cc1)[Ge]O[Mg]</smiles><smiles>C[Si](C)(C)O[Si](C)(C)CCc1ccc(Cl)cc1</smiles>

and the surface-attached benzylic chlorines were used, again in the presence of $\mathrm{Et}_{2} \mathrm{AlCl}$, to initiate the polymerization of styrene and isobutylene. ${ }^{3}$

A recent advance in our laboratories in this area includes the first carbocationic synthesis of (polyisobutylyl)styrene macromer $\mathrm{CH}_{2}=\mathrm{CH}$ $\mathrm{C}_{6} \mathrm{H}_{4} \mathrm{CH}_{2}-\mathrm{PIB}^{4}{ }^{4}$ This synthesis was accomplished by finding controlled conditions under which vinylbenzyl chloride (VBC) initiated the polymerization of isobutylene in the absence of disturbing side-reactions. Further, we felt it to be desirable to obtain macromers with moderate molecular weights, i.e., in the $M_{n}=10,000-30,000$ range. Molecular weights higher than $\sim 30,000$ would have rendered subsequent random copolymerizations of the macromer with conventional small monomers difficult on account of low-molar styryl headgroup concentration. Molecular weights lower than $\sim 10,000$ appeared also undesirable since the ultimate objective was the incorporation of rubbery branches into graft copolymers by copolymerization of the (polyisobutylyl)styrene macromer, and in order to reach the range of rubbery domain with PIB a minimum $M_{n}$ of $\sim 10,000$ deemed to be necessary.

After considerable preliminary studies and characterization research controlled initiation and macromer molecular weights have been obtained by the use of $\mathrm{VBC}-\mathrm{H}_{2} \mathrm{O}-\mathrm{Me}_{3} \mathrm{Al}$ combinations. Surprisingly, we found that $\mathrm{VBC}-\mathrm{Me}_{3} \mathrm{Al}$ mixtures did not initiate isobutylene polymerization in
$\mathrm{CH}_{3} \mathrm{Cl}$ or $\mathrm{CH}_{2} \mathrm{Cl}_{2}$ diluents in the -40 to $-78^{\circ} \mathrm{C}$ range. However, in the presence of water, added in the form of saturated heptane solutions, VBC$\mathrm{Me}_{3} \mathrm{Al}$ systems yielded rapid polymerization of isobutylene and desirable molecular weights.

Independent investigations directed toward the elucidation of details of initiation of isobutylene polymerization with the $\mathrm{VBC}-\mathrm{H}_{2} \mathrm{O}-\mathrm{Me}_{3} \mathrm{Al}-\mathrm{CH}_{3} \mathrm{Cl}$ at $-60^{\circ} \mathrm{C}$ system led to the conclusion ${ }^{4}$ that the macromer is probably formed by the following series of events.

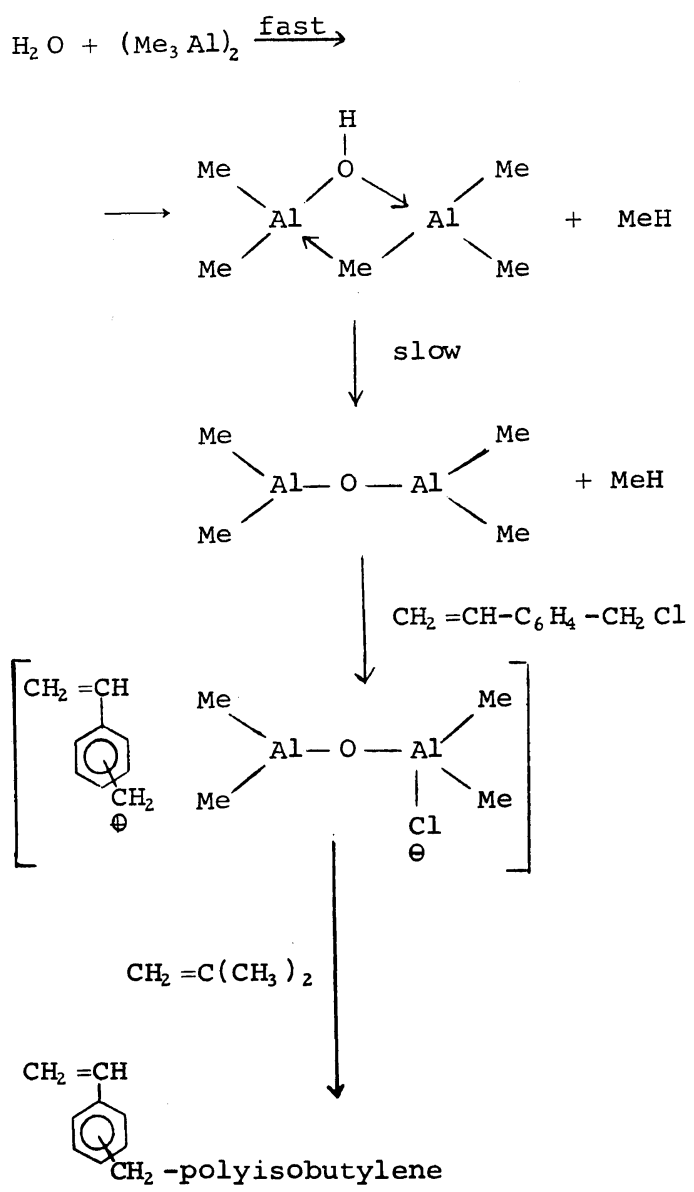

The presence of water is necessary for the formation of the true coinitiator $\left(\mathrm{Me}_{3}\right)_{2} \mathrm{Al}-\mathrm{O}-\mathrm{Al}\left(\mathrm{Me}_{3}\right)_{2}$. This bidentate alkylaluminum is a relatively strong Lewis acid that is able to ionize VBC and thus leads to the polymerization of isobutylene. According to kinetic and other evidence, i.e., Mayo plots, chain transfer to monomer is negligible, and under suitable 
conditions well defined macromers can be obtained. Termination is most likely by methylation of the growing polyisobutylene chain by the complex counter anion.

The (polyisobutylyl)styrene macromer was subsequently copolymerized under typical free-radical conditions (AIBN, toluene, $30^{\circ} \mathrm{C}$ ) with acrylates, for example, butyl acrylate, and thus new graft copolymers have been obtained.

$$
\begin{aligned}
& \overbrace{\mathrm{CH}_{2} \text {-polyisobutylene }}^{\mathrm{CH}_{2}=\mathrm{CH}}+\mathrm{CH}_{2}=\underset{\text { COOC }_{4} \mathrm{H}_{9}}{\mathrm{CH}} \stackrel{\mathrm{R} \cdot}{\longrightarrow} \\
& \text { poly(butyl acrylate-g- } \\
& \text { isobutylene) }
\end{aligned}
$$

\section{Propagation}

One of the most important elusive aims of cationic macromolecular engineering is to establish conditions under which chain transfer to monomer is absent. Notable progress toward this objective has been made during the last year or two. Thus chain transfer to monomer was shown to be blocked by the use of proton traps, e.g., di-t-butylpyridine (DtBP). ${ }^{5}$ We have found that the polymerization of $\alpha$-methylstyrene proceeds rapidly and high-molecular-weight (up to $5 \times 10^{5}$ ) narrowmolecular-weight-distribution (MWD) polymer $\left(M_{w} / M_{n}=1.2-1.6\right)$ can be obtained with the " $\mathrm{H}_{2} \mathrm{O}$ " $-\mathrm{BCl}_{3}-\alpha \mathrm{MeSt}-\mathrm{DtBP}-\mathrm{CH}_{2} \mathrm{Cl}_{2}$ system in the -20 to $-80^{\circ} \mathrm{C}$ range. In the absence of DtBP molecular weights were lower by about one order of magnitude and MWD's were broader $\left(M_{w} / M_{n}>2.0\right)$ than under the same conditions in the presence of DtBP. Detailed fundamental studies have illuminated many aspects of these systems and will be published separately.

Great progress has been made towards elucidating details of inifer systems. ${ }^{6,7}$ Inifers are bifunctional initiating-chain transfer agents which have been used for the preparation of $\alpha, \omega$-difunctional polymers. For example, the $p$-dicumyl chloride- $\mathrm{BCl}_{3}$-isobutylene system yielded $\alpha, \omega$-di $(t$ chloro)polyisobutylene by the following strongly simplified mechanism. ${ }^{6,7}$<smiles>CCCCC(C)(C)OCC</smiles>
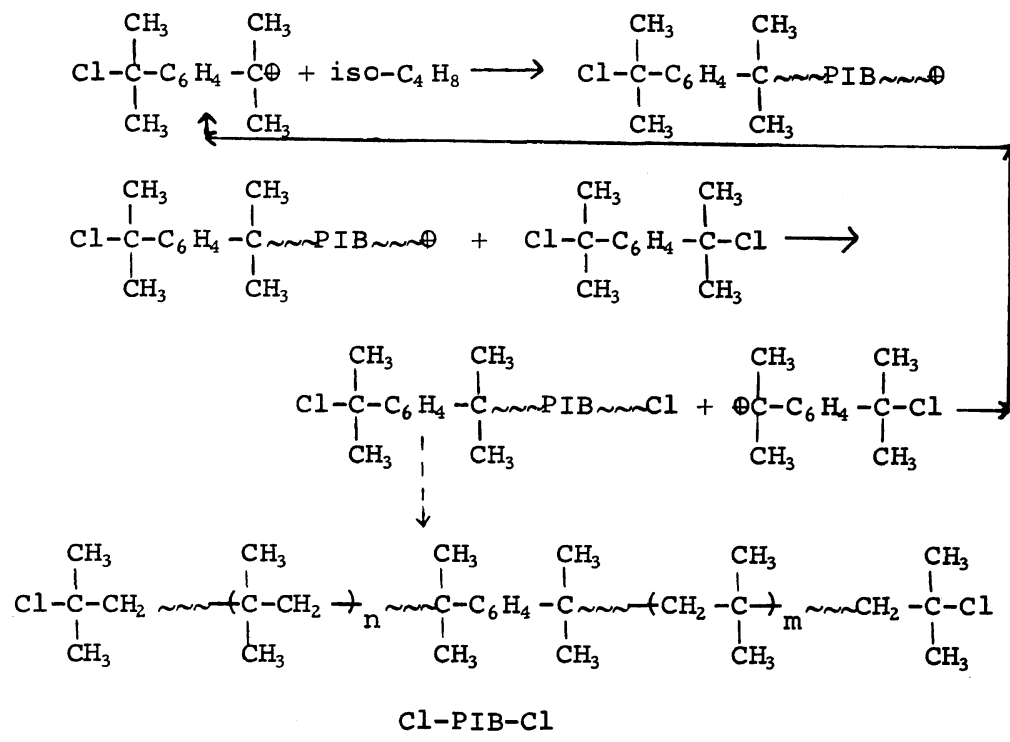
The structure of Cl-PIB-Cl was carefully determined including ${ }^{1} \mathrm{H}$ NMR and UV spectroscopy of suitably low-molecular-weight samples which allowed the characterization of terminal, in-chain and phenyl-adjacent $-\mathrm{CH}_{3}$ and $-\mathrm{CH}_{2}-$ protons. ${ }^{7,8}$ Quantitative endgroup determination was carried out by very accurate dehydrochlorination of $-\mathrm{CH}_{2}\left(\mathrm{CH}_{3}\right)_{2} \mathrm{Cl}$ termini. ${ }^{9}$ Kinetic expressions have been derived correlating molecular weight with monomer and inifer concentration, and temperature. $^{7,10}$ In view of the inifer mechanism, $M_{w} / M_{n}$ should be 1.5 ; this value has been experimentally confirmed. ${ }^{8,10}$ Last but not least the presence and position of $t$-chlorines in Cl-PIB-Cl have been demonstrated by the synthesis of a thermoplastic elastomer triblock copolymer: P $\alpha \mathrm{MeSt}-b$-PIB- $b$ $\mathrm{P} \alpha \mathrm{MeSt} .{ }^{11}$ The synthesis involved the initiation of $\alpha \mathrm{MeSt}$ polymerization by $\mathrm{Cl}-\mathrm{PIB}-\mathrm{Cl}$ in the presence of $\mathrm{Et}_{2} \mathrm{AlCl}$ coinitiator.

$$
\mathrm{Cl}-\mathrm{PIB}-\mathrm{Cl}+\mathrm{Et}_{2} \mathrm{AlCl}+\alpha \mathrm{MeSt} \frac{\mathrm{CH}_{2} \mathrm{Cl}_{2}}{-50^{\circ} \mathrm{C}}
$$$$
\text { poly( } \alpha \text {-methylstyrene)-PIB-poly( } \alpha \text {-methylstyrene })
$$

Just as rewarding were experiments whose aim was the derivatization of $\mathrm{Cl}-\mathrm{PIB}-\mathrm{Cl}$. The regioselective dehydrohalogenation of Cl-PIB- $\mathrm{Cl}$ by hindered base in refluxing THF quantitatively yielded $^{12}$ :<smiles>C=C(C)CCCCC(C)(C)[18CH]C(C)(C)C</smiles>

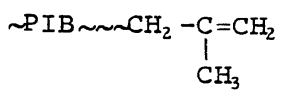

This $\alpha, \omega$-diolefin is a most valuable intermediate toward the synthesis of a variety of products whose investigation is under way in our laboratories. A promising derivative of the $\alpha, \omega$-diene is the $\alpha, \omega$-diol which has been prepared by hydroboration followed by alkaline oxidation ${ }^{13}$ :
Interesting new polyurethanes (PU) have been prepared by reacting this $\alpha, \omega$-primary diol with $2,4-$ toluene diisocyanate in the presence and absence of 1,4-butanediol extender. ${ }^{14}$ PU's with polyisobutylene soft segments promise to exhibit better chemical, oxidative, UV, and hydrolytic stability than conventional polyester or polyether-based products. Investigations directed toward the characterization of these new PU's are under way.

\section{Quasiliving Carbocationic Polymerizations}

Living polymerizations, i.e., polymerization characterized by $R_{\mathrm{t}}=0, R_{\mathrm{tr}, \mathrm{M}}=0$, and $R_{\mathrm{i}}>R_{\mathrm{p}}$, are extremely useful for the preparation of well-defined macromolecules by anionic and oxonium ion techniques. ${ }^{15,16}$ Inspite of numerous attempts ${ }^{17}$ and claims, ${ }^{18-20}$ living carbocationic polymerization has not yet been achieved and the chances of ever attaining it appear to be slim. ${ }^{21}$ Recent kinetic analysis of carbocationic polymerizations have identified systems in which under well-defined conditions (special manner of continuous mixing of monomer with initiating system) chain termination and chain transfer to monomer are reversible or avoidable, and for all practical purposes the system behaves as if $R_{\mathrm{t}}=0$ and $R_{\mathrm{tr}, \mathrm{M}}=0 .{ }^{22}$ Fast $R_{\mathrm{i}}$ was achieved by premixing ingredients of the initiating system. Kinetic equations have been derived according to which the molecular weight of the polymer can be controlled by the cumulative amount of monomer added and initial concentration of initiator: $\overline{D P_{\mathrm{n}}}=M_{\text {total }} /[\mathrm{I}]_{0}$. This equation is very similar to that defining living conditions $\overline{D P_{\mathrm{n}}}=[\mathrm{M}] /$ $[\mathrm{I}]_{0}$. Several carbocationic system have been identified, e.g., " $\mathrm{H}_{2} \mathrm{O}$ "' $-\mathrm{BCl}_{3}-\mathrm{MeSt}, \mathrm{C}_{6} \mathrm{H}_{5}\left(\mathrm{CH}_{3}\right)_{2} \mathrm{Cl}-$ $\mathrm{BCl}_{3}-\alpha \mathrm{MeSt}, t$-BuCl-TiCl ${ }_{4}-\mathrm{ISO}-\mathrm{C}_{4} \mathrm{H}_{8}$, in which the molecular weights obey $M_{\text {total }} /[\mathrm{I}]_{0}$. These systems we propose to call quasiliving systems and the conditions of polymerizations quasiliving conditions. ${ }^{22}$ Figure 1 shows a representative $M_{n}$ versus monomer input plot of a quasiliving system $\left(\mathrm{C}_{6} \mathrm{H}_{5}\left(\mathrm{CH}_{3}\right)_{2} \mathrm{Cl}-\right.$ $\left.\mathrm{BCl}_{3}-\alpha \mathrm{MeSt}\right)$. Importantly, the plots are linear with positive slopes and the straight lines can be readily back extrapolated to the origin. The molecular-<smiles>CC(CO)CCCCC(C)(C)C=CC(C)(C)[18C]CC(C)CO</smiles> 


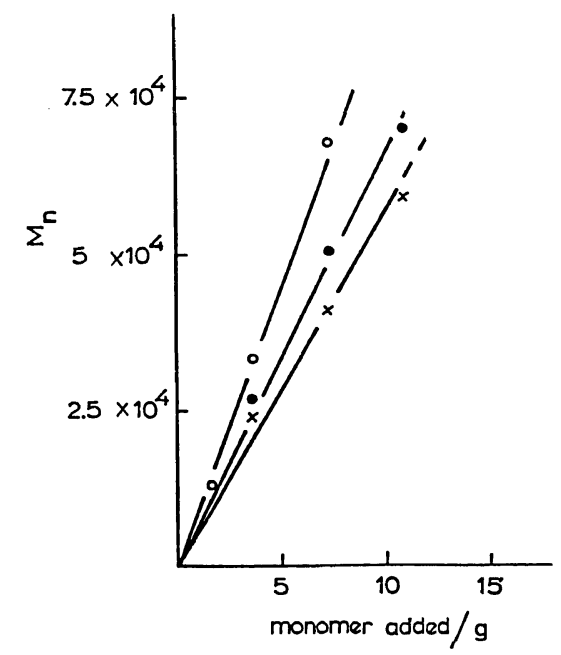

Figure 1. $M_{n}$ vs. monomer input plot of $\mathrm{C}_{6} \mathrm{H}_{5} \mathrm{C}\left(\mathrm{CH}_{3}\right)_{2} \mathrm{Cl}-\mathrm{BCl}_{3}-\alpha \mathrm{MeSt}$ polymerization system at different initiator concentrations; $\times$ and $O,[\mathrm{I}]_{0}=$ $1.88 \times 10^{-4} ; \mathrm{O},[\mathrm{I}]_{0}=9.4 \times 10^{-5}$.

weight dispersion $\left(M_{w} / M_{n}\right)$ continues to decrease from $\sim 2.0$ to $\sim 1.4$ with monomer addition. The quasiliving experiments usually had to be discontinued due to increasing viscosity in the homogeneous stirred systems.

\section{CONCLUSIONS}

The future of carbocationic polymerizations lies toward the tailor-making of well-defined new macromolecules exhibiting desirable physicalchemical properties, i.e., in the realm of macromolecular engineering. The mechanistic elements of this science are now being assembled. Several important reactions have already been found whose control can be exploited by the macromolecular engineer. In this presentation and at a recent major symposium ${ }^{23}$ we have summarized controllable steps to date and illustrated with several specific yetunpublished examples the way rather complex polymer architectures can be assembled.

The versatility of carbocationic macromolecular engineering should be further illustrated by the synthesis of the first graft-block copolymer poly[chloroprene- $g$-(isobutylene- $b$ - $\alpha$-methylstyrene)]. ${ }^{24}$ This synthesis mobilized several elements: controlled initiation, propagation in the absence of chain transfer to monomer, and controlled termination. The first step was the grafting of isobutylene from polychloroprene by $\mathrm{BCl}_{3}$. The graft, the PIB branches of which contained tertiary chlorine termini, was subsequently mixed $\alpha \mathrm{MeSt}$ in a suitable solvent and blocking from was effected by $\mathrm{Et}_{2} \mathrm{AlCl}$ coinitiator. The tertiary chlorine branch-terminus in conjunction with $\mathrm{Et}_{2} \mathrm{AlCl}$ efficiently initiates the polymerization of $\alpha \mathrm{MeSt}$ :
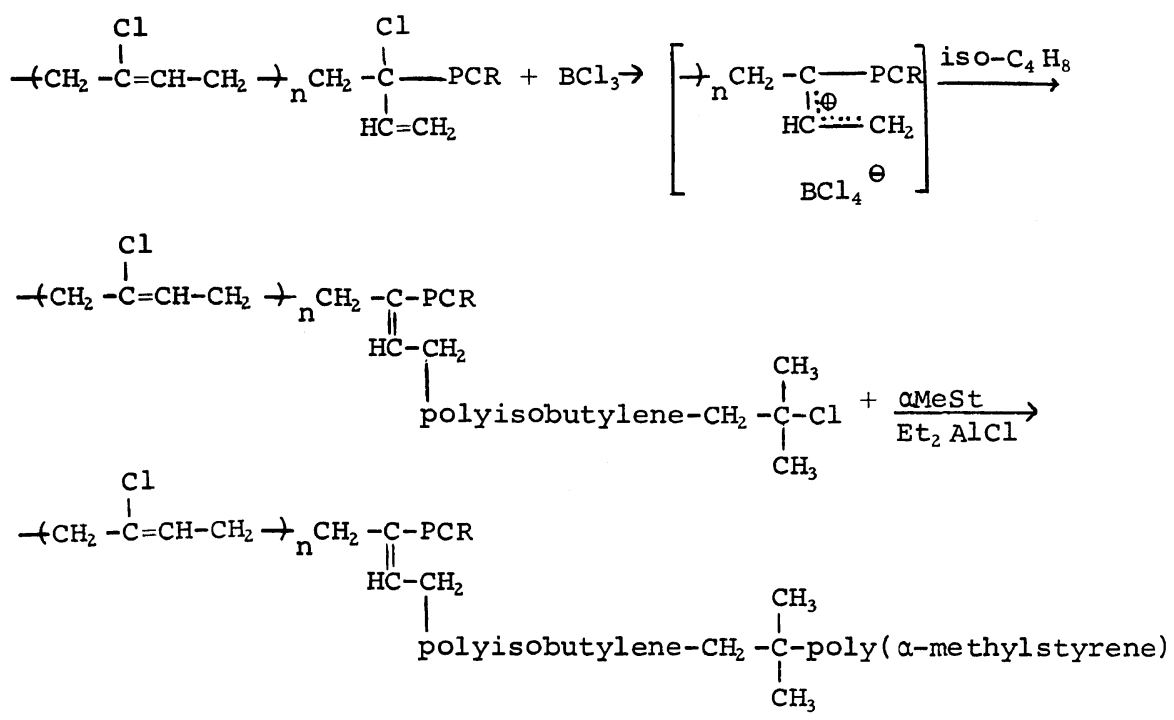
where PCR indicates polychloroprene rubber whose major repeat unit is shown only once for the sake of brevity in the first formula. Grafting is visualized to occur at the sterically less encumbered primary allylic site; the amount of allylic structures in PCR is $\sim 1.5 \%$.

Clearly, variations of such possibilities will lead to an infinite variety of new and unique structures. The time for cooperation between materials scientist and cationic-polymer chemist has arrived jointly to exploit new synthetic possibilities.

Acknowledgements. Partial financial support of the National Science Foundation and Petroleum Research Fund throughout these many years of investigations is gratefully acknowledged.

\section{REFERENCES}

1. "Cationic Graft Copolymerization," J. P. Kennedy, Ed., J. Appl. Polym. Sci., Appl. Polym. Symp., 30, 1-192 (1977).

2. F. Denes, V. Percec, M. Totolin, and J. P. Kennedy, Polym. Bull., in press.

3. A. Vidal, A. Guyot, and J. P. Kennedy, Polym. Bull., in press.

4. J. P. Kennedy and K. Frisch, unpublished results (Akron, 1979).

5. J. P. Kennedy and R. Chou, Polym. Prepr. Am. Chem. Soc., Div. Polym. Chem., 20, 306 (1979).

6. J. P. Kennedy and R. A. Smith, Polym. Prepr., Am. Chem. Soc., Div. Polym. Chem., 20, 316 (1979).
7. J. P. Kennedy and R. A. Smith, J. Polym. Sci., Polym. Chem. Ed., in press.

8. A. Fehérvári, J. P. Kennedy, and F. Tüdös, Poym. Prepr., Am. Chem. Soc., Div. Polym. Chem., 20, 320 (1978).

9. B. Iván, J. P. Kennedy, T. Kelen, and F. Tüdös, $J$. Macromol. Sci., Chem., in press.

10. A. Fehérvári, J. P. Kennedy, and F. Tüdös, $J$. Macromol. Sci., Chem., in press.

11. J. P. Kennedy and R. A. Smith, J. Polym. Sci., Polym. Chem. Ed., in press.

12. J. P. Kennedy, V.S.-C. Chang, R. A. Smith, and B. Ivan, Polym. Bull., 1, 575 (1979).

13. B. Iván, J. P. Kennedy, and V.S.-C. Chang, J. Polym. Sci., Polym. Chem. Ed., in press.

14. B. Iván and J. P. Kennedy, Polym. Prepr., Am. Chem. Soc., Div. Polym. Chem., in press.

15. M. Szwarc, Nature, 178, 1168 (1956).

16. M. Szwarc, M. Levy, and R. Milkovich, J. Am. Chem. Soc., 78, 2656 (1956).

17. J. P. Kennedy, E. Melby, and J. E. Johnston, J. Macromol. Sci., Chem., A8, 463 (1974).

18. T. Higashimura, O. Kishihiro, and T. Takeda, $J$. Polym. Sci., Polym. Chem. Ed., 14, 1089 (1976).

19. T. Higashimura and O. Kishihiro, Polym. J., 9, 87 (1977).

20. T. Higashimura, M. Mitsuhashi, and M. Sawamoto, Macromolecules, 12, 178 (1979).

21. D. C. Pepper, J. Polym. Sci., Polym. Symp., No. 50, 51 (1975).

22. R. Faust, A. Fehérvári, and J. P. Kennedy, to be published (1980).

23. J. P. Kennedy, Makromol. Chem., Suppl., 3, 1 (1979).

24. J. P. Kennedy and S. S. Plamthottam, to be published (1980). 